\title{
Improved White Light Emitting Diode Characteristics by Coating GdAG:Ce Phosphor
}

\author{
Charusheela Joshi ${ }^{\dagger}$ and Pooja Yadav \\ Department of Physics, Shri Ramdeobaba College of Engineering and Management, Nagpur 440013, India \\ S. V. Moharil \\ Department of Physics, R.T.M. Nagpur University, Nagpur 440010, India
}

Received December 5, 2013; Revised January 2, 2014; Accepted February 27, 2014

\begin{abstract}
White LEDs, based on blue LED chips coated with a yellow emitting phosphor (YAG:Ce), have several disadvantages. In this paper, we report the improvement in CRI [Color Rendition Index] using $\mathrm{GdAl}_{5} \mathrm{O}_{12}$ :Ce (GdAG:Ce) and related phosphors for blue LEDs. A modified combustion synthesis route using mixed fuel was used for synthesis route. By using this procedure, we formed the desired compounds in a single step. LEDs were then fabricated by coating the blue LED chips (CREE $470 \mathrm{~nm}, 300$ micron) with the GdAG:Ce phosphor dispersed in epoxy resin. The CRI typically between 65 70 for the YAG:Ce based LED was improved to 87 for LEDs fabricated from the $\mathrm{Gd}(\mathrm{Al}, \mathrm{Ga}) \mathrm{G}$ phosphors.
\end{abstract}

Keywords: Solid state lighting, White LED, Phosphors, Combustion synthesis

\section{INTRODUCTION}

White LEDs, based on blue LED chips coated with yellow emitting phosphor (YAG:Ce), were first reported in 1997 [1] and since then, has been a well known approach to obtain white light. As another approach, white LEDs have been made by coating near ultraviolet ( $\mathrm{n}-\mathrm{UV}$ ) emitting LEDs with a mixture of high efficiency red, green and blue emitting phosphors [2]. Even with the recent improvements in the emission efficiency of LED chips in the near UV-to-deep blue range [3-6], they are still inferior in quality compared to the LED chips coated with YAG:Ce. Hence, the first approach [7] in which blue excitable, yellow phosphor is coated on a blue chip is considered to be more practical. In addition to the poor colour rendering, however, there are several other disadvantages of the YAG:Ce phosphor, which are well documented [8].

${ }^{\dagger}$ Author to whom all correspondence should be addressed: E-mail: charusheela_4253@yahoo.co.in

Copyright (C2014 KIEEME. All rights reserved. This is an open-access article distributed under the terms of the Creative Commons Attribution Non-Commercia
License (http:///creativecommmons.org/licenses/by-nc/3.0) which permits unrestricted noncommercial use, distribution .

\subsection{Drawbacks of YAG:Ce}

Phosphor converted LEDs using YAG:Ce phosphor have high color temperature (CT), typically higher than $6,000 \mathrm{~K}$, and emit only the 'cool white' color. To decrease the CT, it is necessary to move the CT to the right of the coordinated colour temperature (CCT) curve to the right - side in the chromaticity by changing the spectral shape in the visible range. Such a spectral modification cannot be realized by increasing the powder content of the YAG phosphor in typical YAG-based white LED packages.

Also because the chip is small with limited phosphor area, the temperatures near the LED chip can range from 400 to 450 K. Secondly, the efficiency of YAG:Ce phosphor coated LEDs decreases at these temperatures, although the phosphor itself shows much better thermal quenching [9]. This efficiency reduction is related to the concentration quenching at higher temperatures [10]. Another problem associated with the use of YAG:Ce is the "halo effect" (blue/yellow colour separation), which results from the poor mixing of YAG:Ce in the resin due to the high density of YAG, resulting in colour unevenness [11].

For improving CRI and CCT, the emission spectrum can be red-shifted by introducing $\mathrm{Gd}^{3+}[12-14]$ and $\mathrm{Tb}^{3+}[15-17]$ at the $\mathrm{Y}^{3+}$ sites, and blue-shifted by substituting (part of the) $\mathrm{Al}^{3+}$ by $\mathrm{Ga}^{3+}$ 
[18-20]. The effects of these codopants on intensity, emission wavelengths and CRI have been recently reported [21].

In this paper, we report the synthesis and characterization of GdAG:Ce phosphor, and fabricate white LEDs using this phosphor with $470 \mathrm{~nm}$ chips.

\section{EXPERIMENTS}

$\mathrm{Gd}_{3} \mathrm{Al}_{5} \mathrm{O}_{12}(\mathrm{GdAG})$ : Ce $(0.7 \mathrm{~mol} . \%)$ phosphors were prepared by combustion synthesis. Instead of the conventional solution combustion synthesis, we used a modified procedure to form the desired compounds in a single step. Reagent grade (Indian Rare Earths, Ltd.) rare earth oxides/carbonates were dissolved in nitric acid to convert them into corresponding nitrates. The nitrates were dried by prolonged, gentle warming. Stoichiometric amounts of hydrated nitrates of yttrium, aluminium and cerium were thoroughly mixed with urea/glycine. The nitrate - to - fuel ratios were calculated by the method described earlier $[22,23]$. Due to the presence of large water of crystallization in aluminium nitrate, a thick paste was formed. A china dish containing this paste was placed in a furnace preheated to $500^{\circ} \mathrm{C}$. Within minutes, the paste foamed and a flame was produced, which lasted for several seconds. The china dish was immediately removed from the furnace.

$\mathrm{X}$-ray diffraction patterns were recorded on the Philips PANalyticalX'pert Pro diffractometer. PL characteristics in the range of 200 700 $\mathrm{nm}$ at room temperature were studied using a Hitachi F-4000 spectrofluorimeter with $1.5 \mathrm{~nm}$ spectral slit width. Colour coordinates of the phosphor were calculated using the software Colour Calculator 2.0.0 (Radiant Imaging).

All the lines matched exactly well with those of ICDD file $73 \sim 1,371$. Some additional weak lines mixed in the noise may be due to the carbonaceous matter that was formed during combustion synthesis

The phosphor in desired quantity was dispersed in a transparent silicone resin (Wells Electronic Materials Company, 5012-2A and 5012-2B), and the resulting epoxy resin was coated onto a blue LED chip (CREE $470 \mathrm{~nm}, 300$ micron) to fabricate an LED. The electroluminescence (EL) spectra, colour temperature, CIE chromaticity coordinates, CRI and lumen output at room temperature of the fabricated LED were measured using a $300 \mathrm{~mm}$ integrating sphere and lumen meter (Hangzhou Zhongwei Photoelectricity Company ZVision ZWL 3900). The measurements were carried out at $3.2 \mathrm{~V}, 20 \mathrm{~mA}$.

\section{RESULTS AND DISCUSSION}

Figure 1 shows the XRD pattern of the GdAG:Ce phosphor that was prepared by combustion synthesis. In our experiments, when urea was used as the fuel, the combustion products were poorly crystallized. Gadolinium nitrate does not have exothermic reaction with urea. Hence, we tried a mixed (Glycine + urea) fuel. Glycine has exothermic reaction with Gadolinium nitrate and urea with aluminum nitrate. An excellent match between the XRD pattern of the GdAG:Ce synthesized using mixed fuel was obtained with the ICDD file 73 1,371. Phase pure GdAG was thus obtained in a single step combustion process without any additional thermal treatment when mixed fuel (Glycine + urea) was used. Activation with $\mathrm{Ce}^{3+}$ or addition of $\mathrm{Ga}$ was also attempted by adding cerrous nitrate or Ga nitrate, respectively, to the combustion mixture. Figure 2 shows the PL results for the phosphor so prepared. The excitation spectrum of YAG:Ce (Fig. 2, curve a) consists of several bands; those around 453 and $340 \mathrm{~nm}$ are clearly seen. At $460 \mathrm{~nm}$ excitation, intense emission is observed

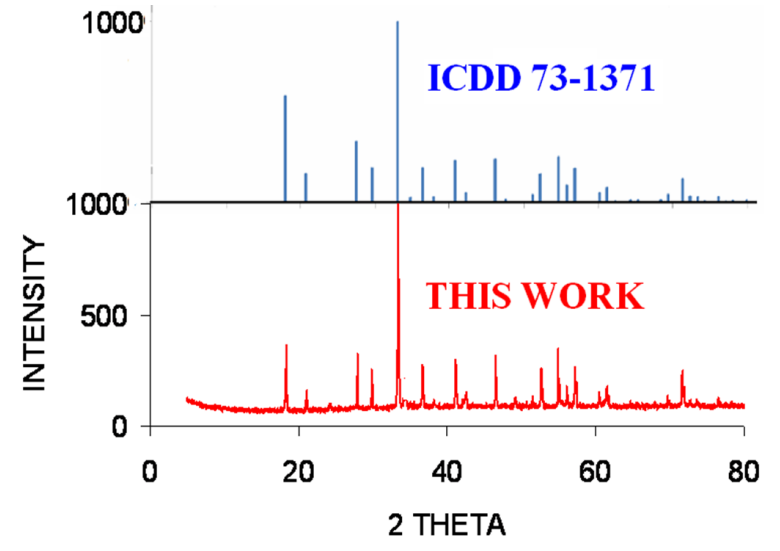

Fig. 1. XRD pattern of GdAG ICDD file no. 73 1,371 and sample in this work.

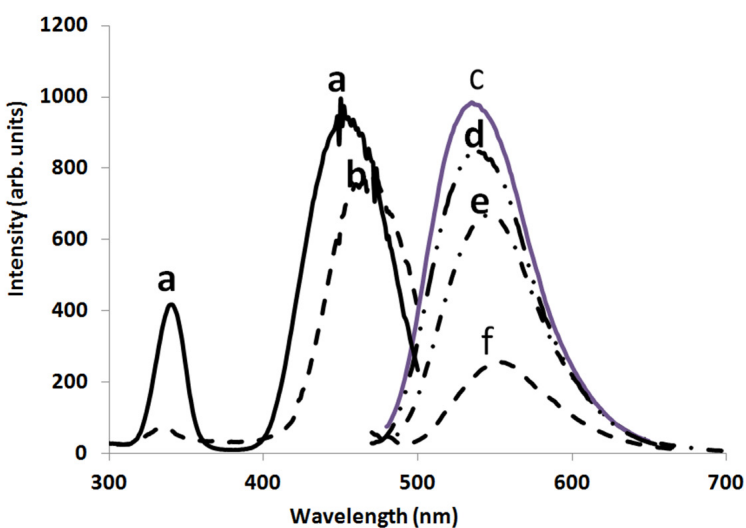

Fig. 2. PL characteristics of (a) excitation of YAG:Ce with emission at $535 \mathrm{~nm}$, (b) excitation of GdAG:Ce with emission at $545 \mathrm{~nm}$, (c) emission of YAG:Ce at $460 \mathrm{~nm}$, (d) emission of (Y,Gd)AG:Ce at $460 \mathrm{~nm}$ excitation, (e) emission of $\mathrm{Gd}(\mathrm{Al}, \mathrm{Ga}) \mathrm{G}: \mathrm{Ce}$ at $470 \mathrm{~nm}$ excitation, and (f) emission of GdAG:Ce at $470 \mathrm{~nm}$ excitation.

with a broad maximum at $535 \mathrm{~nm}$. (Fig. 2, curve c).

Figure 2, curve $\mathrm{b}$ describes the excitation spectrum of GdAG:Ce phosphor peaking at $465 \mathrm{~nm}$. This spectrum being broad has good overlap with $470 \mathrm{~nm}$ wavelength. Thus, the excitation maximum is red-shifted by $12 \mathrm{~nm}$. The emission spectrum of GdAG is scanned with $470 \mathrm{~nm}$ excitation shifted to $552 \mathrm{~nm}$; thus, the emission red-shifted by about $17 \mathrm{~nm}$. But the intensity decreased (Fig. 2, curve f).

In order to shift the emission wavelength without drop in intensity, (Y,Gd)AG:Ce was prepared. Figure 2, curve d refers to the emission spectrum. There is a marginal red shift by about $2 \mathrm{~nm}$, without much drop in intensity.

In order to retain the red shift of GdAG:Ce but to increase the emission intensity, $10 \%$ of $\mathrm{Al}$ in GdAG:Ce was replaced by Ga to prepare $\left(\mathrm{Gd}_{2.979} \mathrm{Ce}_{0.021}\right)\left(\mathrm{Al}_{4} \mathrm{Ga}\right) \mathrm{O}_{12}$, henceforth regarded as $\mathrm{Gd}(\mathrm{Al}, \mathrm{Ga}) \mathrm{G}: \mathrm{Ce}$.

The peak emission wavelength shifts to the right (Fig. 2, curve e) at $545 \mathrm{~nm}$ without greatly affecting intensity. The excitation curve for $\mathrm{Gd}(\mathrm{Al}, \mathrm{Ga}) \mathrm{G}$ :Ce is the same as that of GdAG:Ce phosphor and thus, has a better overlap with chip wavelength of 470 nm. For this reason, $470 \mathrm{~nm}$ chips were used to fabricate phosphor coated LEDs.

LEDs fabricated by coating YAG:Ce on the blue chips have poor CRI, typically in the range 65-70. Shifting the spectrum to 


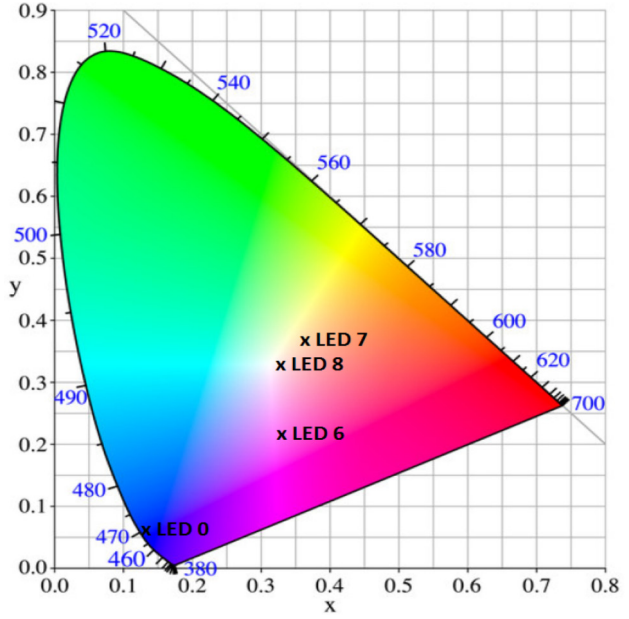

Fig. 3(a). Colour coordinates of LEDs fabricated with $\mathrm{Gd}_{2.979} \mathrm{Al}_{4}$ $\mathrm{GaO}_{12}: \mathrm{Ce}_{0.021}$ phosphor as described in Table 1. LED8 represents $\mathrm{Y}_{2.879} \mathrm{Gd}_{0.1} \mathrm{Al}_{5} \mathrm{O}_{12}: \mathrm{Ce}_{0.021}$ having CIE colour coordinates $\mathrm{x}=0.32, \mathrm{y}=0.32$.

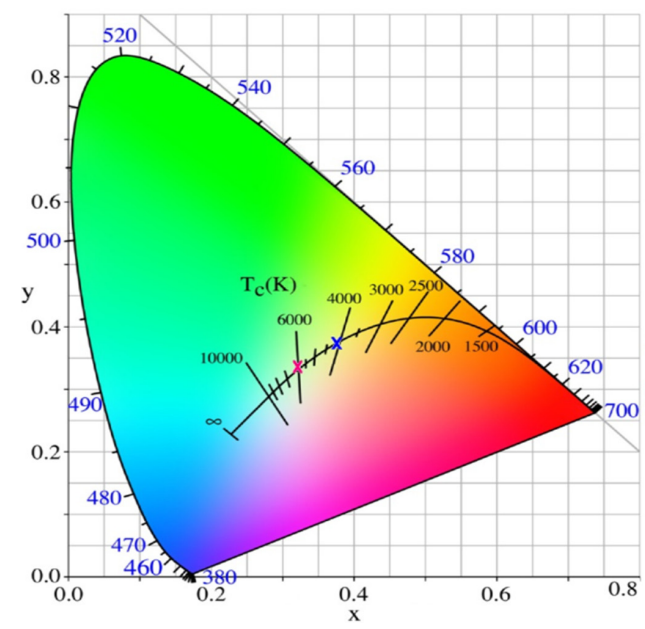

Fig. 3(b). Coordinated colour Temperature (CCT) of LEDs fabricated by coating a $470 \mathrm{~nm}$ chip with $\mathrm{Gd}_{2.979} \mathrm{Al}_{4} \mathrm{GaO}_{12}: \mathrm{Ce}_{0.021}$ phosphor as described in table 1. CCT for LED6 is 5,821 K and that of LED7 is 4,309 K.

longer wavelengths or adding a red component can improve CRI To ascertain the performance of the $470 \mathrm{~nm}$ chips with $\mathrm{Gd}(\mathrm{Al}, \mathrm{Ga})$ G:Ce phosphor with respect to these parameters, LEDs were fabricated by coating the $470 \mathrm{~nm}$ chips with GdAG:Ce phosphors in proportions given in Table 1. Table 1 lists the various parameters of LED0? LED7 as measured by the Lumen meter (ZWL 3900). LED8 represents $\mathrm{Y}_{2.879} \mathrm{Gd}_{0.1} \mathrm{Al}_{5} \mathrm{O}_{12}$ : $\mathrm{Ce}_{0.021}$ having CIE colour coordinates $\mathrm{X}=0.32, \mathrm{y}=0.32$.

\subsection{Color Coordinates and CCT of LEDs}

Figure 3(a) represents CIE $\mathrm{x}$ and y coordinates of some LEDs. LED 6 and 7 both have good CIE coordinates and hence good CRI of 86.4 and 82.9 respectively, which approach the centre of the chromacity triangle. LED8 has CIE coordinates of $x=0.32, y=$ 0.32 , and hence, has an ideal position exactly at the centre of the chromaticity triangle.

Figure 3(b) represents the colour temperatures of LED6 with $\mathrm{Tc}=5821 \mathrm{~K}$ and LED7 with $\mathrm{Tc}=4309 \mathrm{~K}$. With change in the ratio of GdAG phosphor in the epoxy resin, the blue colour from the diode chip is converted more to phosphor emission.
Table 1. List of various parameters for LEDs fabricated by coating the 470 nm chips with $\mathrm{Gd}_{2.979} \mathrm{Al}_{4} \mathrm{GaO}_{12}: \mathrm{Ce}_{0.021}$.

\begin{tabular}{ccccccccc}
\hline & $\begin{array}{c}\text { Phosphor } \\
\text { to epoxy } \\
\text { ratio by } \\
\text { wt.\% }\end{array}$ & $\begin{array}{c}\mathrm{I} \\
(\mathrm{mA})\end{array}$ & $\begin{array}{c}\mathrm{V}_{\mathrm{f}} \\
(\mathrm{V})\end{array}$ & $\begin{array}{c}\mathrm{P} \\
(\mathrm{mw})\end{array}$ & $\begin{array}{c}\mathrm{Tc} \\
(\mathrm{K})\end{array}$ & CIE-x & CIE-y & Ra \\
\hline \hline 470 nm & -- & & & & & & & \\
LED 0 & & 20 & 3.33 & 6.4069 & 1923 & 0.1318 & 0.0692 & 0 \\
\hline LED1 & $1 \%$ & 20 & 3.19 & 7.4947 & 3618 & 0.1781 & 0.1257 & 0 \\
\hline LED2 & $2 \%$ & 20 & 3.21 & 7.1724 & 5204 & 0.1883 & 0.1419 & 0 \\
\hline LED3 & $3 \%$ & 20 & 3.28 & 5.1677 & & 0.2201 & 0.1891 & 0 \\
\hline LED4 & $4 \%$ & 20 & 3.26 & 4.0293 & 17221 & 0.2687 & 0.2456 & 75.1 \\
\hline LED5 & $5 \%$ & 20 & 3.33 & 1.9398 & 3260 & 0.4381 & 0.441 & 70.9 \\
\hline LED6 & $6 \%$ & 20 & 3.2 & 2.819 & 5821 & 0.3264 & 0.3163 & 86.4 \\
\hline LED7 & $7 \%$ & 20 & 3.27 & 2.191 & 4309 & 0.367 & 0.3633 & 82.9 \\
\hline
\end{tabular}

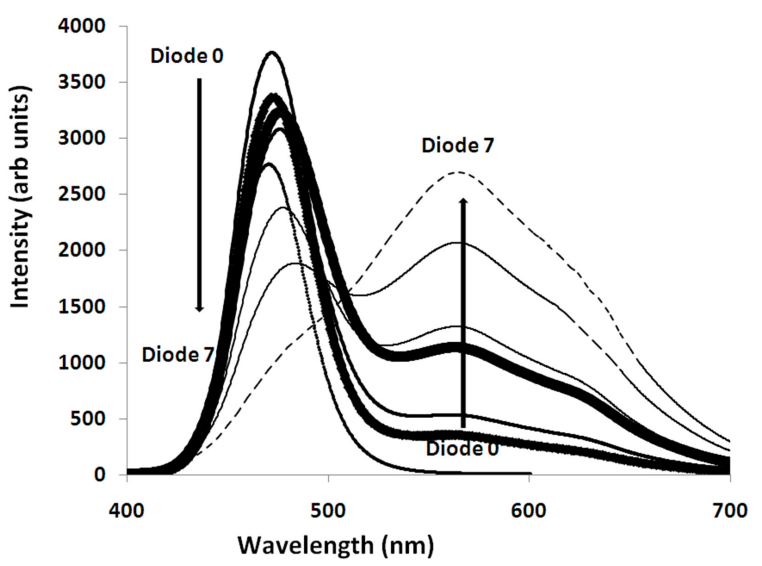

Fig. 4. Emission spectra of LED0- LED7. LED0 represents the uncoated blue diode, while LED 7 represents the diode with white emission. LED2-LED6 occupy intermediate positions described in Table 1.

Figure 4 represents the spectra of LEDs $0-7$ with the mentioned compositions in Table 1. The downward arrow represents the successive drop in blue emission and the upward arrow represents the corresponding increase in yellow component, which lead to white emission, which in turn improve the CRI from 75 to 86.

\section{CONCLUSIONS}

Commercial YAG:Ce phosphor has low CRI of 70. We tried to improve CRI by changing the phosphor to GdAG. GdAG:Ce was prepared by combustion synthesis using mixed fuel. LEDs prepared from the $470 \mathrm{~nm}$ chips coated with GdAG:Ce considerably improved CRI up to 86 .

\section{ACKNOWLEDGMENTS}

We thank the Department of Science and Technology, New Delhi for Women Scientist award to PJY.

\section{REFERENCES}

[1] S. Nakamura and G.. Fasol, The Blue Laser Diode: GaN Based Light Emitters and Lasers(Heidelberg, Spring, 1997).

[2] Y.Xu, L.Chen, Y.Li, G..Song, Y.Wang, W.Zhuang, and Z.Long, 
Appl. Phys.Lett., 92, 021129 (2008) [DOI: http://dx.doi. org $/ 10.1063 / 1.2835703]$

[3] M.Khizar, Z.Y.Fan, K.H.Kim, J.Y.Lin, H.X.Jiang, Appl. Phys.Lett. 86, 173504 (2005) [DOI: http://dx.doi.org/10.1063/1.1914960].

[4] L. Chen, C. C. Lin, C. W. Yeh, and R. S. Liu, Materials, 3, 2172 (2010).

[5] R. J.Xie, N.Hirosaki, Y. Li, and T. Takeda, Materials, 3, 3777 (2010),

[6] S. Ye, F. Xiao, Y.X. Pan, Y.Y. Ma, Q.Y. Zhang, Mater. Sci. Engg. R, 71, 1 (2010) [DOI: http://dx.doi.org/10.1016/ j.mser.2010.07.001].

[7] Y. Shimizu, K. Sakano, Y. Noguchi, and T. Moriguchi., U. S. Patent; 5, 998, 925 (1999).

[8] P. F. Smet, A. B. Parmentier, and D.Poelman, J. Electrochem. Soc., 158, R037 (2011) [DOI: http://dx.doi. org/10.1149/1.3568524]

[9] J. Ueda, S. Tanabe, and T. Nakanishi, J. Appl. Phys., 110, 053102 (2011) [DOI: http://dx.doi.org/10.1063/1.3632069].

[10] V. Bachmann, C. Ronda, and A. Meijerink, Chem. Mater., 21, 2077 (2009) [DOI: http://dx.doi.org/10.1021/cm8030768].

[11] T. Maeda, S. Oshio, K.Iwama, H.Kitahara, T. Ikeda, H. Kamei, Y.Hanada, and K.Sakanoue,Patent US, 7,422,504 (2008).

[12] T. Y. Tien, E. F. Gibbons, R. G. DeLosh, P. J. Zacmanidis, D. E. Smith, and H. L. Stadler J. Electrochem. Soc., 120, 278 (1973) [DOI: http://dx.doi.org/10.1149/1.2403436].

[13] S. UysalSatilmis, A. Ege, M. Ayvacikli, A. Khatab, E. Ekdal, E.J Popovici, M. Henini, and N. Can, Opt. Mater., 34, 1921(2012) [DOI: http://dx.doi.org/10.1016/j.optmat.2012.06.002].
[14] A.Latynina, M. Watanabe, D. Inomata, K. Aoki, Y. Sugahara, E. G.. V?llora, and K.Shimamura, J.Alloys.Compds., 553, 89(2013) [DOI: http://dx.doi.org/10.1016/j.jallcom.2012.11.096].

[15] Y. S. Lin, R. S. Liu, and B. M. Cheng, J. Electrochem. Soc., 152, J41 (2005) [DOI: http://dx.doi.org/10.1149/1.1896307].

[16] S. Fujita, A. Sakamoto, and S. Tanabe, IEEE J. Sel. Top. Quantum. Electron., 14, 1387 (2008) [DOI: http://dx.doi.org/10.1109/ JSTQE.2008.920285].

[17] V.P. Dotsenko, I.V. Berezovskaya, E.V. Zubar, N.P. Efryushina, N.I. Poletaev, Y. A. Doroshenko, G..B. Stryganyuk, and A.S.Voloshinovskii, J.Alloys.Compds., 550, 159 (2013) [DOI: http://dx.doi.org/10.1016/j.jallcom.2012.09.053].

[18] R. Hansel, S. Allison, and G. Walker, J. Mater. Sci., 45, 146 (2010) [DOI: http://dx.doi.org/10.1007/s10853-009-3906-9].

[19] K. Kamada, T.Yanagida, J. Pejchal, M.Nikl, T. Endo, K.Tsutumi, Y. Fujimoto, A.Fukabori, and A. Yoshikawa, J. Phys. D: Appl. Phys., 44, 505104(2011) [DOI: http://dx.doi.org/10.1088/00223727/44/50/505104].

[20] P.Dorenbos and J.Lumin, 134, 310 (2013) [DOI: http://dx.doi. org/10.1016/j.jlumin.2012.08.028].

[21] T. Han, S. Cao, L. Peng, D. Zhu, C. Zhao, M. Tu, and J. Zhang,Mat.Res.Bull., 47, 1618 (2012).

[22] J.J. Kingsley, K. Suresh, and K.C. Patil, J. Mater. Sci., 25, 1305 (1990).

[23] J.J.Kingsley, N. Manickam, and K.C. Patil, Bull. Mater. Sci., 13, 179 (1990) [DOI: http://dx.doi.org/10.1007/BF02744944]. 